\title{
A Field Study on Pile response to Blast-Induced Ground Motion
}

\author{
L.B. Jayasinghe ${ }^{1}$, Z.Y. Zhao ${ }^{1 \dagger}$, A.T.C. Goh ${ }^{1}$, H.Y. Zhou ${ }^{2}$, Y.L. Gui ${ }^{3}$, M. Tao ${ }^{4}$ \\ ${ }^{1}$ School of Civil and Environmental Engineering, Nanyang Technological University, Singapore \\ ${ }^{2}$ Key Laboratory of Urban Security and Disaster Engineering of Ministry of Education, Beijing \\ University of Technology, China \\ ${ }^{3}$ School of Civil Engineering and Geosciences, Newcastle University, UK \\ ${ }^{4}$ School of Resources and Safety Engineering, Central South University, Changsha, China.
}

\begin{abstract}
A series of field tests using controlled blasting was conducted at a location in the North Western part of Singapore to assess the behaviour of pile foundations subjected to ground excitation. The field tests involved three piles with different pile head fixity conditions. The piles were instrumented with strain gauges to evaluate the bending moments and axial force along the piles. For the fixed-head piles, the maximum bending moment occurred at the pile head level. For free-head pile exhibited higher bending moments close to the mid-height of the pile and zero bending moment at the pile head due to the absence of restraints at the top. For all cases, the axial force was maximum value at the pile head.
\end{abstract}

Keywords: Rock blasting; Field tests; Piles; Ground vibration; Strain

\section{Introduction}

In a construction blasting operation, the main function of explosives is to break the rocks through the release of large amounts of energy. However, only a portion of the energy is consumed in breaking the rocks and the remaining energy is dissipated in the form of seismic waves expanding rapidly outward from the blast as ground vibrations and air blast. Ground vibrations from rock blasting are a particular concern as the vibration which has a high amplitude and short duration can cause damage to nearby structures in one or several ways. For example, blasting induced ground vibration may compact the foundation soil on which the structure is built, resulting in distress to the structure. When the natural frequency of the

\footnotetext{
$\dagger$ Corresponding author. Tel: +65 67905255

E-mail: CZZHAO@ntu.edu.sg
} 
structural member(s) coincides with the frequency of the impinging ground vibrations, resonant vibrations are produced and cause substantial damage to the structure. In addition, ground vibrations which have high frequency and high amplitude may also have an impact on the various components of the structure so that the strength of the member or material is exceeded. Moreover, soil can be liquefied beneath or adjacent to the structure as a result of blasting, resulting in substantial damage to foundations and consequently to the superstructure.

Generally, for the safer performance of any structure, the foundation should have sufficient strength and stability. Nowadays, high-rise buildings, bridges and other smart infrastructures depend largely on the pile foundation for transferring the heavy loads from the superstructure above through weak compressible soil strata into deeper, competent soil layers which have adequate capacity to carry these loads. In engineering practice, many piles are designed only for carrying vertical loading, as typically the vertical loads (from the gravity weight of the structure) are significantly larger than the horizontal loads such as wind loading. Short duration, high frequency and high amplitude loads such as ground vibrations from rock blasting may also have an impact on the pile foundation system. They can induce lateral and bending stresses in the piles and cause significant damage, resulting in differential settlement and tilting of the superstructure, leading to weakening of the structure [1]. A small magnitude of a blast, if it occurs in close proximity of a pile, it may cause the pile to fail which can subsequently lead to progressive failure of the whole structure [2, 3]. It is therefore important when designing structures that may be subjected to the ground vibrations from rock blasting to assess the stability and vulnerability of a pile foundation system against ground-borne vibrations.

The influences of ground vibration on pile foundations have been studied by researchers using small-scale experiments and numerical simulations. Abdoun et al. [4] and Wilson et al. [5] carried out small-scale centrifuge tests to study the dynamic response of pile foundations in liquefying sand during seismic loading. Shim [6] also has carried out a series of 70-g centrifuge tests to investigate the blast wave propagation and response of piles embedded in saturated sand. Aluminium piles with hollow circular section at different standoff distances from buried the explosive charge were used in the test. Kamijo et al. [7] conducted vibration tests at a large-scale mining site to investigate liquefaction phenomena and dynamic responses of pile foundations. Ground motions from large-scale blasting operations were used 
for the vibration tests. It is found that bending moments were maximum at the pile heads, regardless of input motion levels. However, the moment distribution shapes differed with the degree of the liquefaction in the test pit Ashford et al. [8] conducted full-scale tests to assess the dynamic response of a single pile, a four-pile group, and a nine-group subjected to lateral spreading. The steel pipes were $11.5 \mathrm{~m}$ long with an outer diameter of $318 \mathrm{~mm}$ and thickness of $10.5 \mathrm{~mm}$. The test results indicated that the pile head displacement and moment in the single pile were significantly higher than those observed in the pile groups. It is also found that the degree of fixity at the pile tips had a great influence on the moments of individual piles in the group. Large bending moments are developed in the pile when the larger degree of fixity into the dense soil layer. Durante et al. [9] performed 1-g shaking table tests to investigate the dynamic response of a single pile and a pile group subjected to both horizontal and vertical dynamic shaking. The studies have shown that the kinematic interaction may be significant near the pile head if rotations are prevented and close by the interface between soil layers with different stiffness [10-12].

A number of researchers have developed numerical methods to analyse the performance of pile foundations subjected to dynamic lateral loads [13-17]. Hao et al. [18] presented a numerical method to calculate the elastic and inelastic single pile responses to blast loads. The pile-soil system was modelled as beam-column elements supported by both vertical soil springs of Winkler foundation. However, this method cannot incorporate the radial and threedimensional components of interaction. The shear stress which is acting along the side of the pile is ignored by this method. Since a 3D FE analysis requires a considerable amount of computational cost for generating input and interpretation results, it has not been used frequently until recently for the soil-pile interaction analyses. Huang et al. [19] studied the dynamic response of pile-soil-structure interaction (PSSI) system under blasting load. Solid elements were used to simulate piles, soil and pile cap, while beam elements were used to simulate columns and beams of the superstructure. In this study, they applied a velocity-time history curve of blasting seismic wave on the tip of the pile. The authors have concluded that because of the maximum shear stress at the top of the pile, the connection of piles and pile cap are easily damaged and pile-soil contact pressure increases at the pile ends. Jayasinghe et al. [20] developed a fully coupled method to treat the blast response of a pile foundation in saturated soil and the effects of end restraint of pile head and the number and spacing of piles within a group were investigated later [21]. 
The objective of the present study is to investigate the impact of rock blasting on pile foundations. Thus, a series of field tests was conducted at a location in the north western part of Singapore to study the pile response and possible damage when subjected to ground excitation of various intensities. In this paper, a brief description of the test set-up and the pile instrumentation is presented first. Then, the measured results and the calculated bending moments and axial forces are presented and discussed.

\section{Test set-up}

In Singapore, bored cast-in-situ concrete piles are commonly used as the foundation for highrise buildings. Chang and Broms [22] reported that approximately 200000 to $400000 \mathrm{~m}$ length of large diameter bored piles are installed in Singapore each year, because of the high capacity, relatively low costs, easy length adjustment, and low noise and vibration levels during construction. The diameters of these piles vary from $600 \mathrm{~mm}$ to $1500 \mathrm{~mm}$ depending on the design load on the pile. The piles can be end-bearing piles, friction piles or a combination of end bearing and friction piles. Socketed piles are widely used in the Singapore construction industry as well as all over the world. Socketed piles are usually endbearing piles which are socketed into a weathered/soft rock. Socketing piles into a soft or weathered rock will improve the axial and lateral load capacities of piles when the surrounding soil above the rock is weak.

Before the field blast tests, soil investigation works were carried out to establish the subsurface ground conditions. The layout of the test site is shown in Fig. 1. The test site consisted of medium-grained granite bedrock, overlain by residual soils [23]. The rock-cores retrieved from the boreholes, indicated the occurrence of Bukit Timah Granite rocks [24]. The slightly weathered granite G (II), was encountered at depths of between $0.6 \mathrm{~m}$ and $11 \mathrm{~m}$ below the ground level.

In the field test, three instrumented bored cast-in-situ concrete piles ( 1 single pile and a pile group of 2 piles) were used to investigate the response of piles subjected to rock blasting induced ground vibration. All the piles were $600 \mathrm{~mm}$ in diameter, and an average length of 8m. Two piles (pile A and C) were socketed into rock while the other one (pile B) was embedded in soil. Moreover, two piles (pile A and B) had pile caps to prevent the rotation at pile head and the other pile (pile C) had a free end at the pile head level. The dimensions of 
the pile caps were $1.5 \mathrm{~m}$ (width) x $1.5 \mathrm{~m}$ (length) x $0.9 \mathrm{~m}$ (height). A ground beam which has cross section of $0.5 \mathrm{~m} \times 0.5 \mathrm{~m}$ was used to connect the pile A and B.

The compressive strength of the concrete was $53.7 \mathrm{~N} / \mathrm{mm}^{2}$ at 28 days and all the piles were nominally reinforced with 8 numbers of $16 \mathrm{~mm}$ diameter of high strength deformed bars (characteristics strength of $460 \mathrm{~N} / \mathrm{mm}^{2}$ ) for the main vertical bars and $10 \mathrm{~mm}$ diameter of high strength deformed bars (characteristics strength of $460 \mathrm{~N} / \mathrm{mm}^{2}$ ) at $200 \mathrm{~mm}$ centre to centre spacing for the stirrups as shown in Fig. 2.

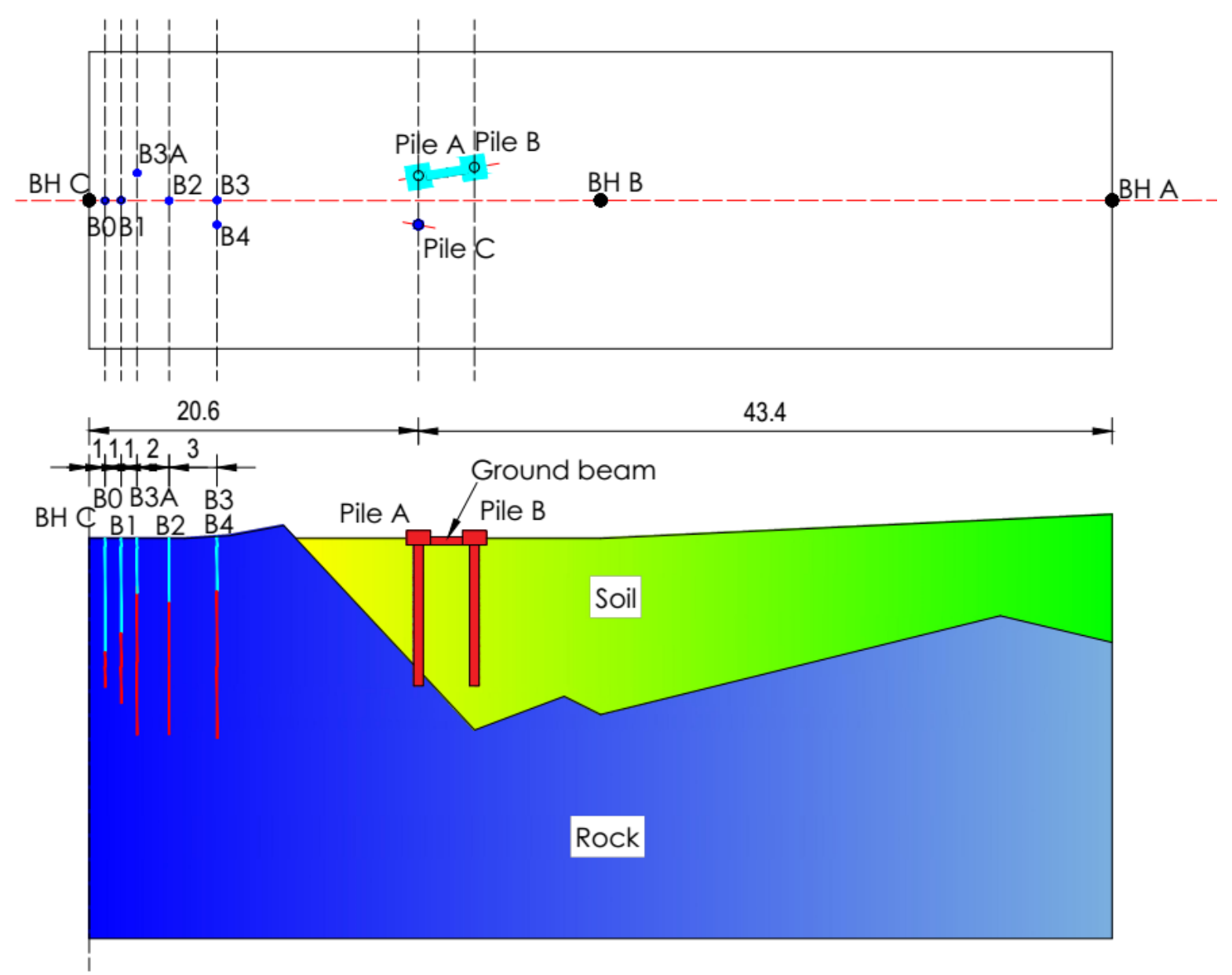

Fig. 1. Plan and section view of the piles and blast holes locations (units of meters) 


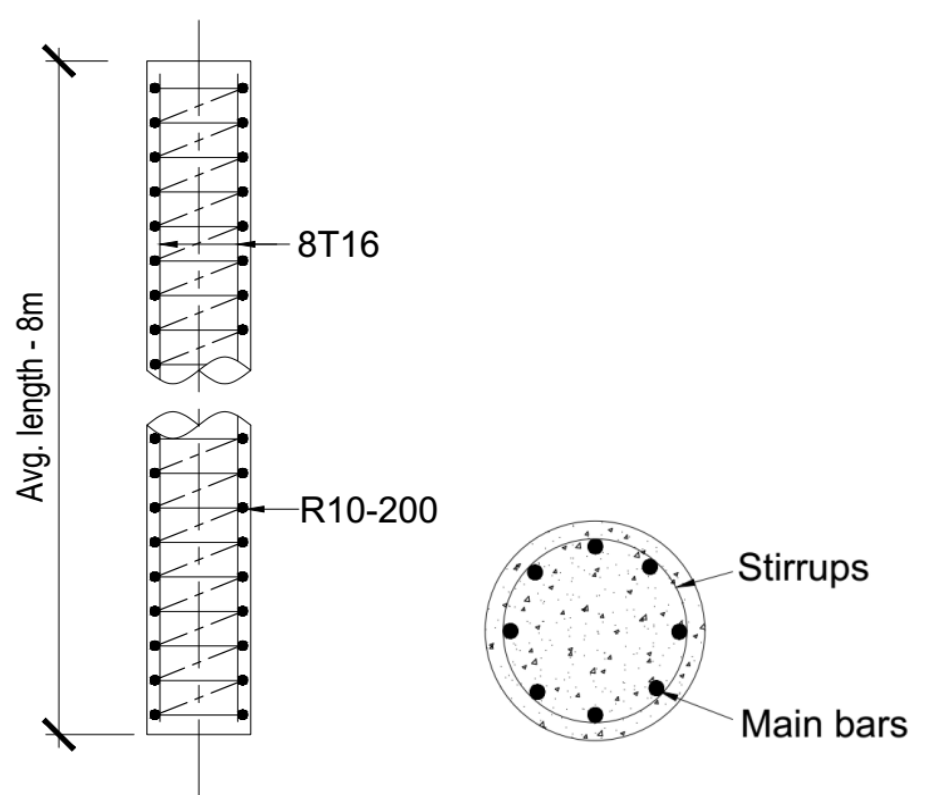

Fig. 2. Pile reinforcement details

In total, six numbers of blast tests were carried out as summarized in Table 1 . The first 2 blast tests (B0 and B1) were carried out to check and test the data logger's settings, and the remaining four blast tests $(\mathrm{B} 2, \mathrm{~B} 3, \mathrm{~B} 3 \mathrm{~A}$ and $\mathrm{B} 4)$ were conducted to study the pile response under blast-induced ground vibration. The sequence of the tests was B0, B1, B2, B3, B3A and B4, respectively. Each blast hole was $76 \mathrm{~mm}$ in diameter and the explosives used in the tests were Ammonium Nitrate-Fuel Oil (ANFO). The detonator used in the test was an electronic detonator. Also shown in Fig. 2 are the locations of the blast holes (denoted by the notations B0, B1 etc.). All the distances are measured from the reference borehole $\mathrm{C}$ (BH C), which was used in the soil investigation works.

Table 1. Summary of blast tests

\begin{tabular}{cccc}
\hline Blast test & $\begin{array}{c}\text { Distance from } \\
\text { BH C (m) }\end{array}$ & $\begin{array}{c}\text { No. of } \\
\text { holes }\end{array}$ & $\begin{array}{c}\text { ANFO } \\
\text { weight }(\mathbf{k g})\end{array}$ \\
\hline B0 & 1 & 1 & 6.25 \\
B1 & 2 & 1 & 12.5 \\
B2 & 5 & 1 & 24 \\
B3 & 8 & 2 & 58.1 \\
B3A & 3 & 3 & 84.9 \\
B4 & 8 & 6 & 168.5 \\
\hline
\end{tabular}


The other important concern in this test was pile instrumentation. The main objective of pile instrumentation was to obtain the pile response along the pile shaft. The instrumentation consisted of installing strain gauges and force transducers at selected levels of the pile. The pile deformation and blast pressures on the pile were measured using strain gauges and force transducers, respectively. The strain gauges and force transducers locations are shown in Fig. 3.

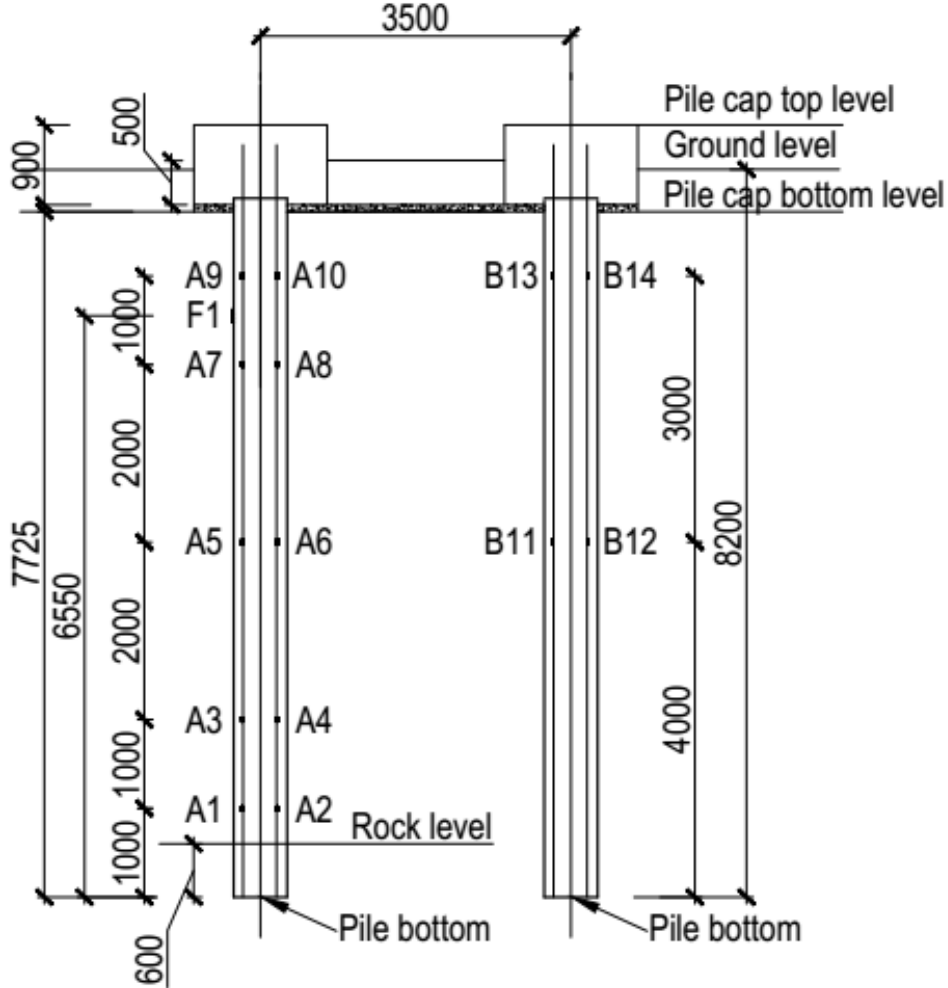

Pile A

Pile B

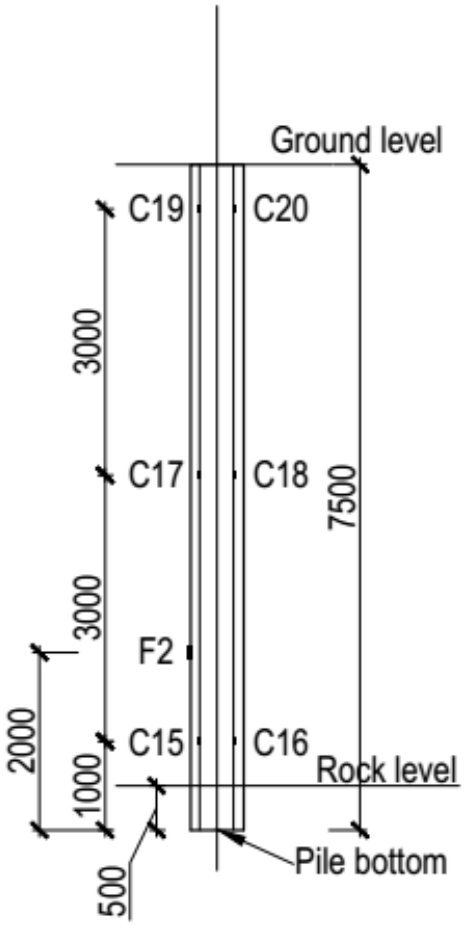

Pile C

Fig. 3. Pile instrumentation plan (units of millimeters)

In total, 20 numbers of linear strain gauges of $10 \mathrm{~mm}$ gauge length were used for the evaluation of the pile deformation. Also, two numbers of force transducers were used to measure the blast load acting on the instrumented piles. The strain gauges were attached at different elevations on two of the main rods, diametrically opposite, as shown in Fig. 4(a). After mounting the gauges, they were secured with the protective bandage and the electric cable from each gauge was safely secured along with the main rod. The force transducers were attached onto the rebar cage using a hydraulic cylinder as shown in Fig. 4(b). Subsequently the instrumented rebar cage was lowered into the borehole, and the force 
transducers were extended into the borehole soil surface connecting a hydraulic hand pump to a hydraulic cylinder. 10 numbers of strain gauges (A1 to A10 in Fig. 3) were installed on the pile $A$ at $1 \mathrm{~m}, 2 \mathrm{~m}, 4 \mathrm{~m}, 6 \mathrm{~m}$ and $7 \mathrm{~m}$ heights from the pile bottom. 4 (B11 to B14) and 6 (C15 to C20) numbers of strain gauges were attached on the pile B and pile $\mathrm{C}$, respectively, at $1 \mathrm{~m}$, $4 \mathrm{~m}$ and $7 \mathrm{~m}$ heights from the pile bottom as illustrated in Fig. 3. The force transducers, F1 and F2 (in Fig. 3), were installed on the pile A and pile $\mathrm{C}$ at $6.55 \mathrm{~m}$ and $2 \mathrm{~m}$ height from the pile bottom, respectively.

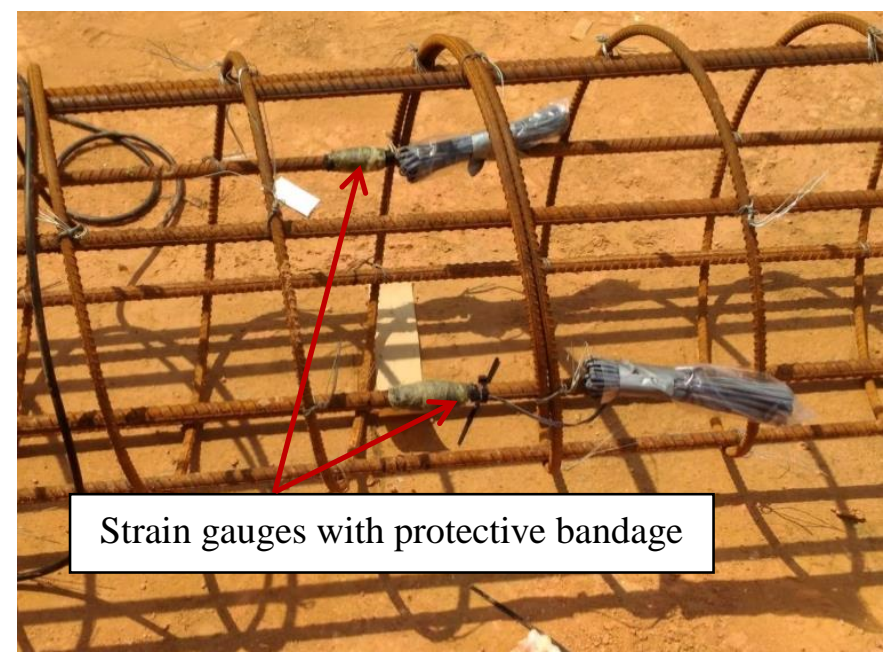

(a)

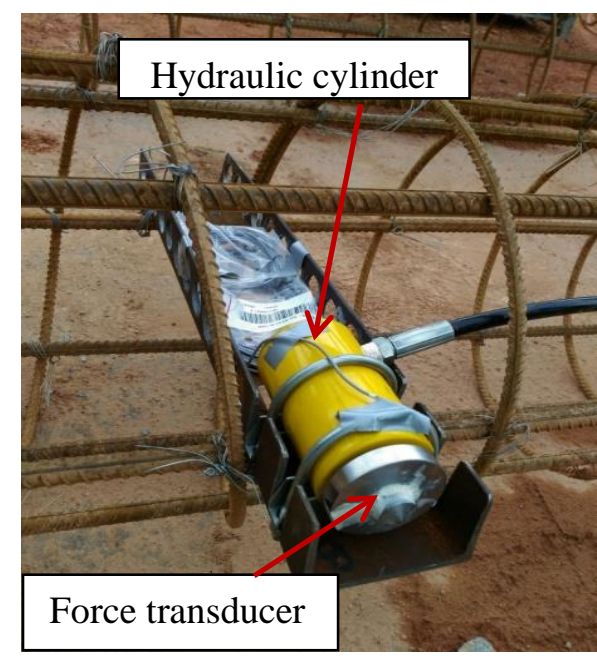

(b)

Fig. 4. Pile instrumentation (a) strain gauges on two main rods (b) force transducer fixture

\section{Results and Discussion}

As described above, a total of 3 piles were instrumented with electrical resisting foil-type strain gauges. When the instrumented pile is deformed, the foil experiences a variation in electrical resistance, which varies linearly with strain. All strain gauges were calibrated and zeroed before each test. The strain gauges were attached at different elevations on the two of the main rods at opposite sides of the piles as illustrated in Fig. 5 to obtain the strains from which the bending moments and axial force along the lengths of the piles could be determined. If the pile is subjected to axial deformation only, the strains on both sides of pile must be same (i.e. $\varepsilon_{1}=\varepsilon_{2}=\varepsilon$ ). However, if the pile is subjected to bending deformation only, the strains on both sides along the pile will be symmetric (i.e. $\varepsilon_{1}=-\varepsilon_{2}=\varepsilon$ ). Since the piles are subjected to both bending and axial deformations by blasting induced ground vibration, the strain gauges readings at the opposite sides of the piles ( $\varepsilon_{1}$ and $\varepsilon_{2}$ in Fig. 5) are not the same. 
Thus, the deformations are generated by both bending moment $\left(\varepsilon_{\mathrm{BM}}\right)$ and axial force $\left(\varepsilon_{\mathrm{AF}}\right)$ are calculated as given in Eqs. (1) and (2).

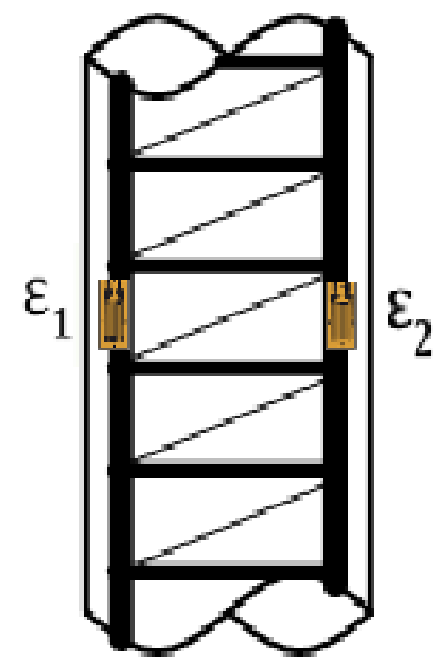

(a)

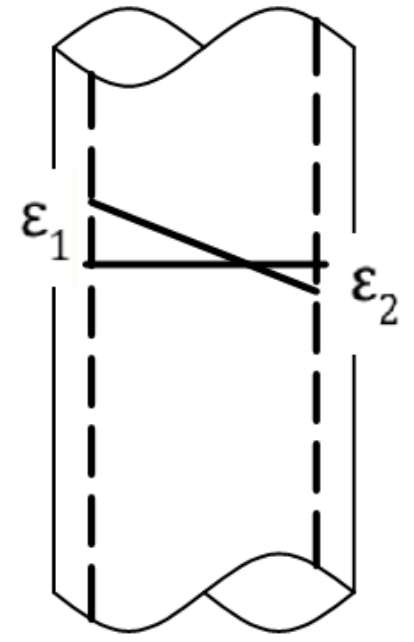

(b)

Fig. 5. (a) Strain gauges at the two main rods at opposite sides of the pile (b) typical strain responses of the strain gauges

$$
\begin{aligned}
& \varepsilon_{\mathrm{BM}}=\frac{\varepsilon_{1}-\varepsilon_{2}}{2} \\
& \varepsilon_{\mathrm{AF}}=\frac{\varepsilon_{1}+\varepsilon_{2}}{2}
\end{aligned}
$$

Considering the elasticity of the pile and from beam theory, the bending moment (BM) and axial force (AF) are evaluated using the measured bending and axial strains as given in Eqs. (3) and (4).

$$
\begin{aligned}
& B \mathrm{M}=\frac{\varepsilon_{1}-\varepsilon_{2}}{2} \quad \mathrm{E}_{\mathrm{p}} \mathrm{I}_{\mathrm{p}}\left(\frac{2}{D}\right) \\
& A F=\frac{\varepsilon_{1}+\varepsilon_{2}}{2} \\
& \mathrm{E}_{\mathrm{p}} \mathrm{A}_{p}
\end{aligned}
$$

In the above equations, $E_{p}, I_{p}, A_{p}$ and $D$ are the elastic modulus, the second moment of area, the cross sectional area and the diameter of the pile, respectively.

Pile A had 10 strain gauges to investigate the vertical distributions of pile bending moments and axial forces. Piles $\mathrm{B}$ and $\mathrm{C}$ had 4 and 6 strain gauges, respectively, to compare their 
response with pile A. Fig. 5 show some typical strain time-histories measured at $4 \mathrm{~m}$ height from the pile bottom of each pile for B3 blast test. A5 and A6, B11 and B12, and C17 and C18 strain gauges were installed at $4 \mathrm{~m}$ height from the pile bottom on the two main rods at opposite sides of pile A, pile B and pile C, respectively (Fig. 3). Pile A was the leading pile of the 2-pile group while pile $\mathrm{B}$ was the trailing pile of the group and pile $\mathrm{C}$ was the single pile with no pile cap at the pile head. As shown in Fig. 6, the strains measured in strain gauges appear almost symmetrical with respect to the horizontal axis and in the opposite phase, which suggests the pure bending of the pile. In addition, when the ground vibration stops, the strain time-histories show a residual deformation that produces a residual bending moment and axial force. The corresponding bending moments of each pile are shown in Fig. 7.

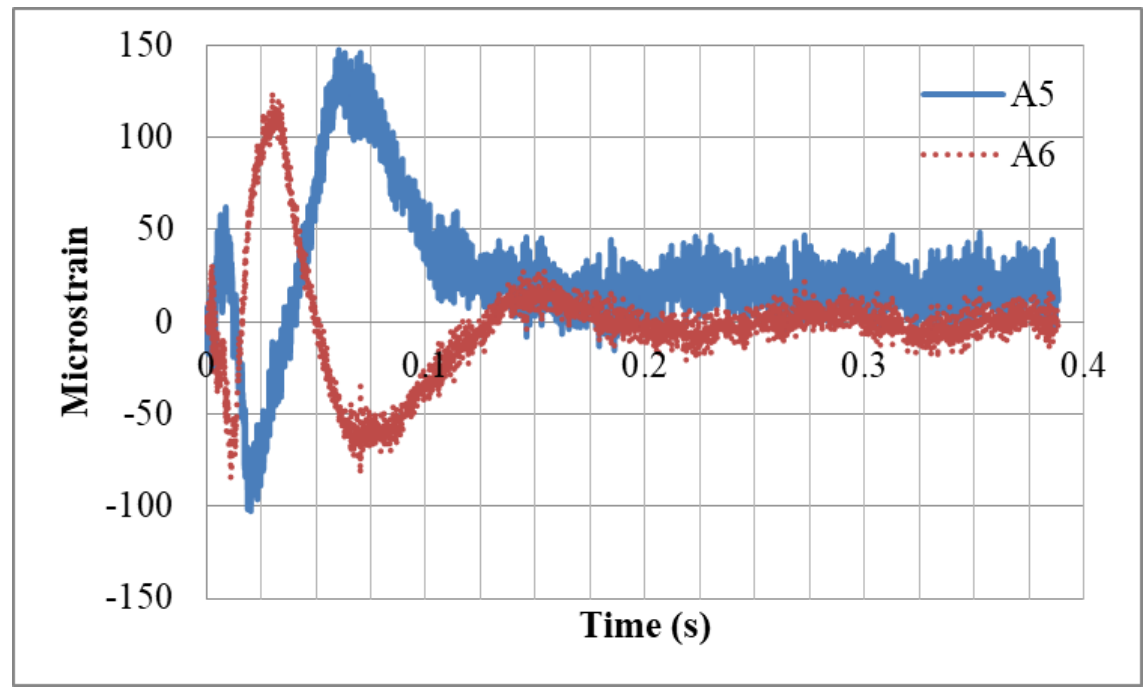

(a)



(b) 


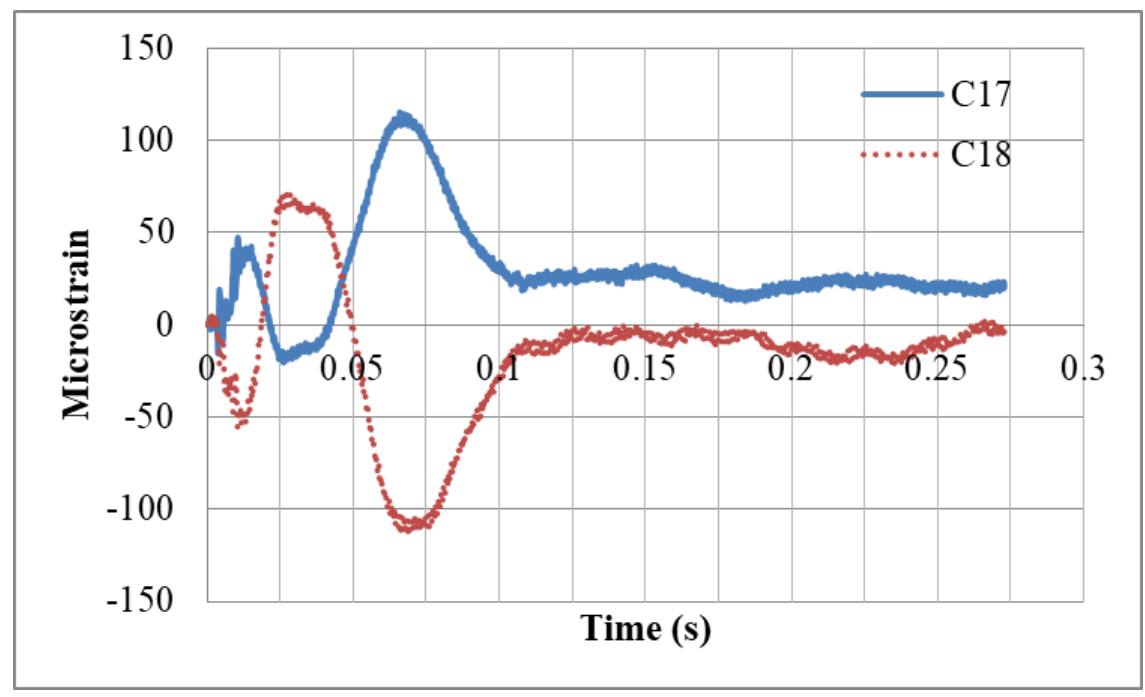

(c)

Fig. 6. Measured strain time-histories at $4 \mathrm{~m}$ height from pile bottom of (a) pile A (b) pile B (c) pile C for B3 blast test

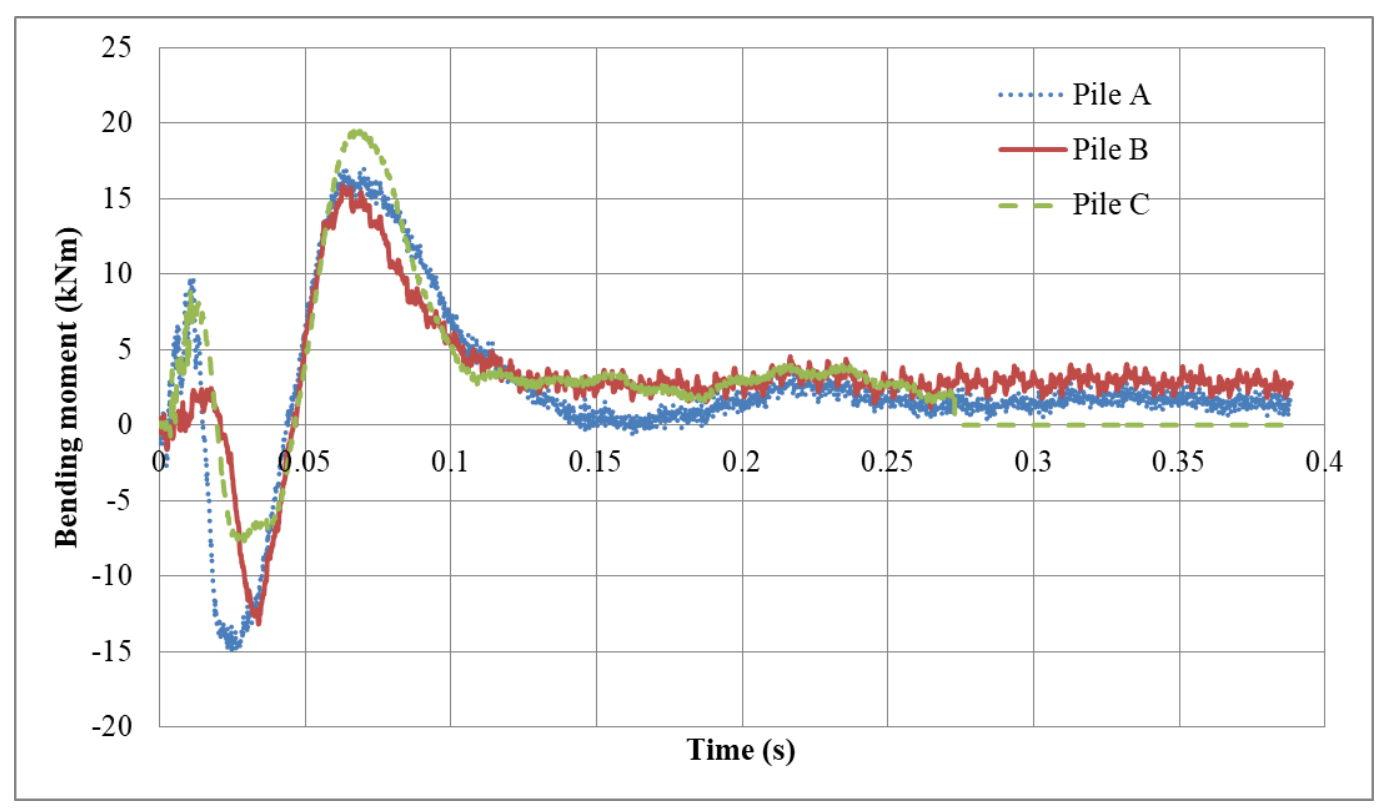

Fig. 7. Time-histories of computed bending moments at $4 \mathrm{~m}$ height from pile bottom of each pile for B3 blast test

As described above, the measured ground vibrations in all the sensors from blast tests B2, B3, B3A and B4 were used to study the pile response under blast-induced ground vibration. Fig. 8 shows the distribution of the maximum bending moments of each pile along the pile length. The horizontal green colour dashed line and red colour dotted line in the plots indicate the ground level (GL) and pile cap bottom level, respectively. It can be seen that the moment distribution shapes differed in each test. Bending moments at the pile cap level could not be 
measured due to practical issues to install the strain gauges at that level. However, the bending moments are expected to be having a maximum value at the pile head in pile A and pile $\mathrm{B}$ due to the pile caps provided at the top of piles $\mathrm{A}$ and $\mathrm{B}$. The bending moments in pile B were smaller compared to the pile A, possibly because of the shielding effect of pile A.

Pile $\mathrm{C}$ exhibits higher bending moments at $3.5 \mathrm{~m}$ of pile depth (close to the mid-height of the pile) compared with piles A and B because of the absence of restraints at the pile head. Also, pile $\mathrm{C}$ has a significantly smaller bending moment at $0.5 \mathrm{~m}$ below the pile head. This is expected for a free-head pile, since the bending moment at the pile head must be zero.

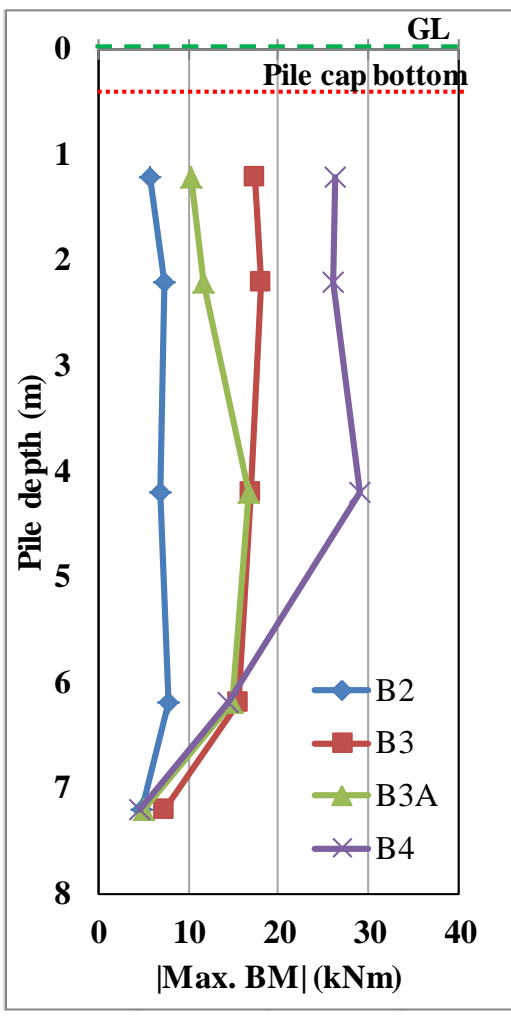

(a)

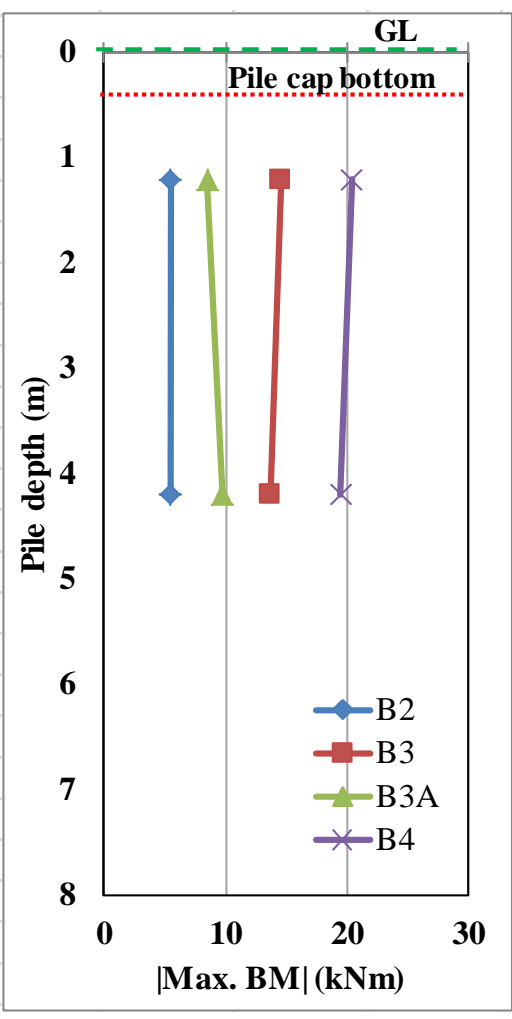

(b)

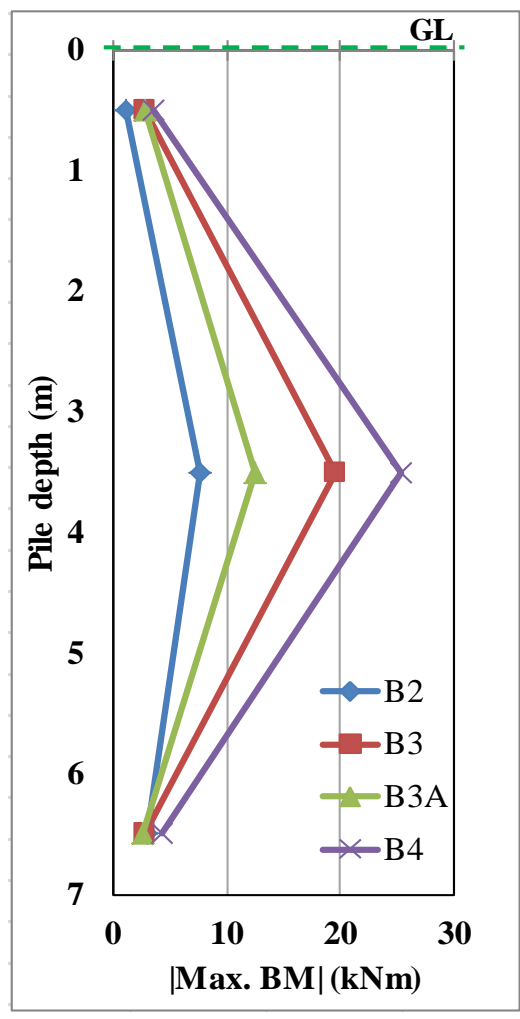

(c)

Fig. 8. The distribution of maximum BMs of (a) Pile A (b) Pile B (c) Pile C

Moment distributions along the length of Pile A at the ends of the first and second blast tests (B2 and B3) are presented in Fig. 9(a). As expected, the moment after the second test (B3) was larger than the moment after the first test (B2) because the pile experienced larger movement. Fig. 9(b) shows the residual bending moments along the length of pile A after each test. Similar to the observation in Fig 9(a), the moment after each test was larger than the moment after the previous blast. However, the negative bending moments at the pile bottom has decreased in blast test B3A and B4. This might be due to the cracks developed in 
the rock around the pile from the previous blasts (B2 and B3) and hence, loss the fixity between the rock and pile. Thus, it is clear that repeated blast loading acting on the pile has some influence on the residual bending moments developed along the pile length.

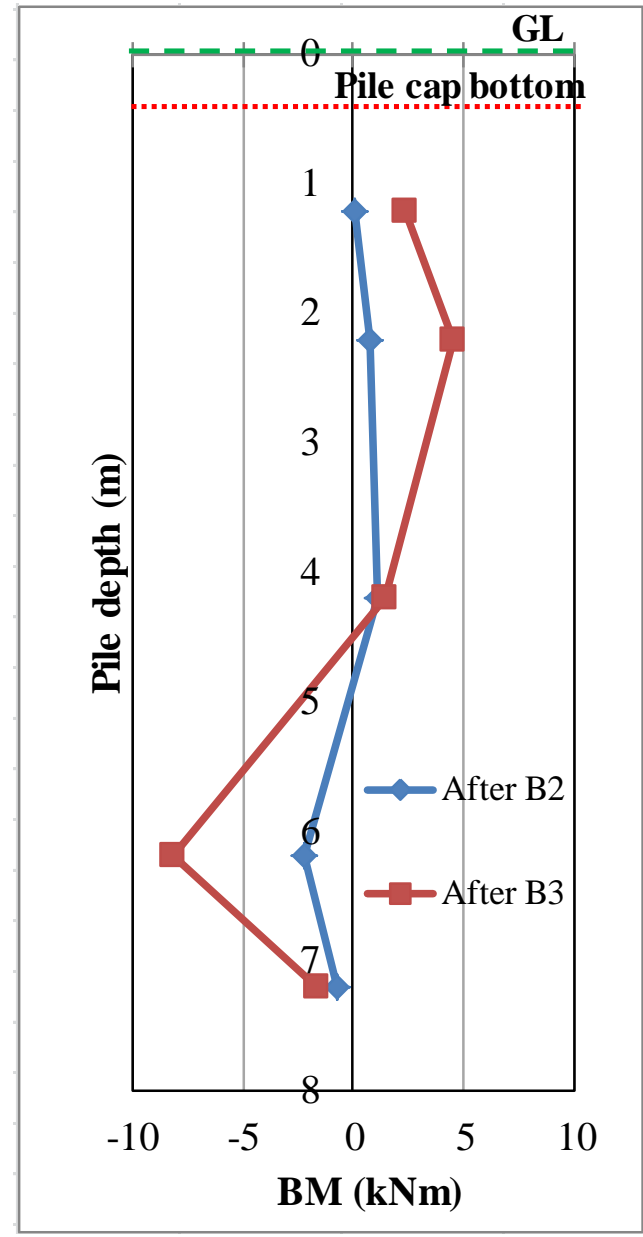

(a)

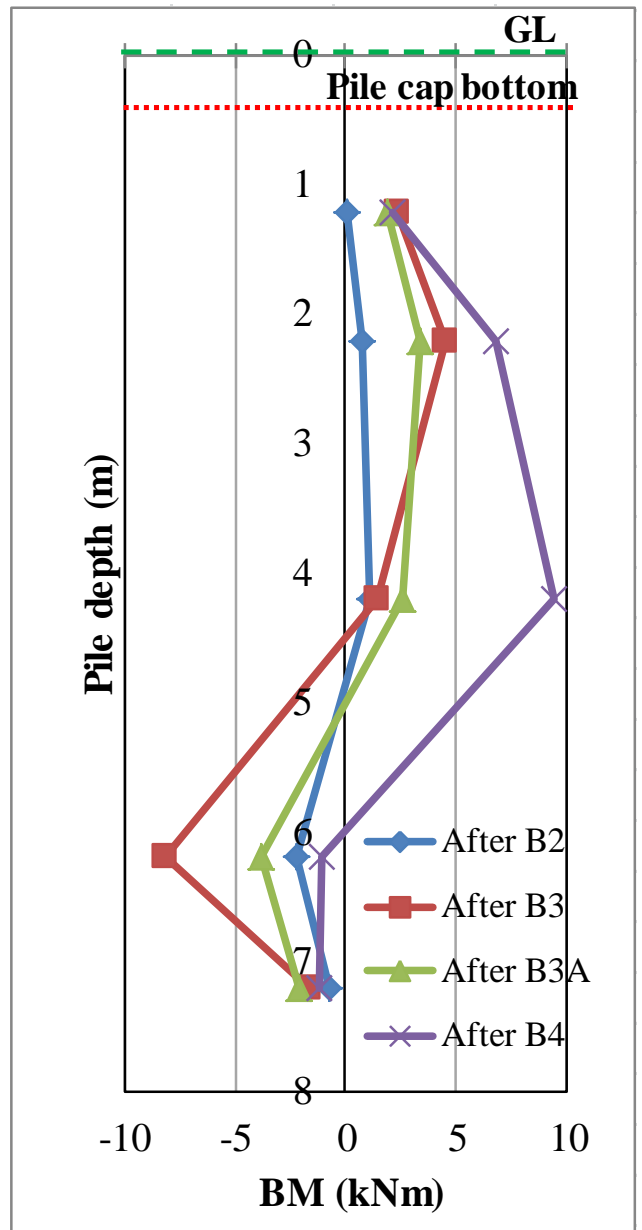

(b)

Fig. 9. Moment profiles of Pile A after (a) blast tests B2 and B3 (b) each blast test

Fig. 10 shows the distribution of the maximum axial forces of each pile along the pile length. For blast load B2, only $56 \mathrm{kN}$ was measured at the level of the last strain gauge and $68 \mathrm{kN}$ was measured at the top level of pile A. However, only $152 \mathrm{kN}$ and $80 \mathrm{kN}$ were measured at the level of first and last strain gauges, respectively, on the pile A for blast test B4. It can be clearly seen that the axial forces were largest at the top of the piles for all cases. This observation is consistent with the findings from [25]. 


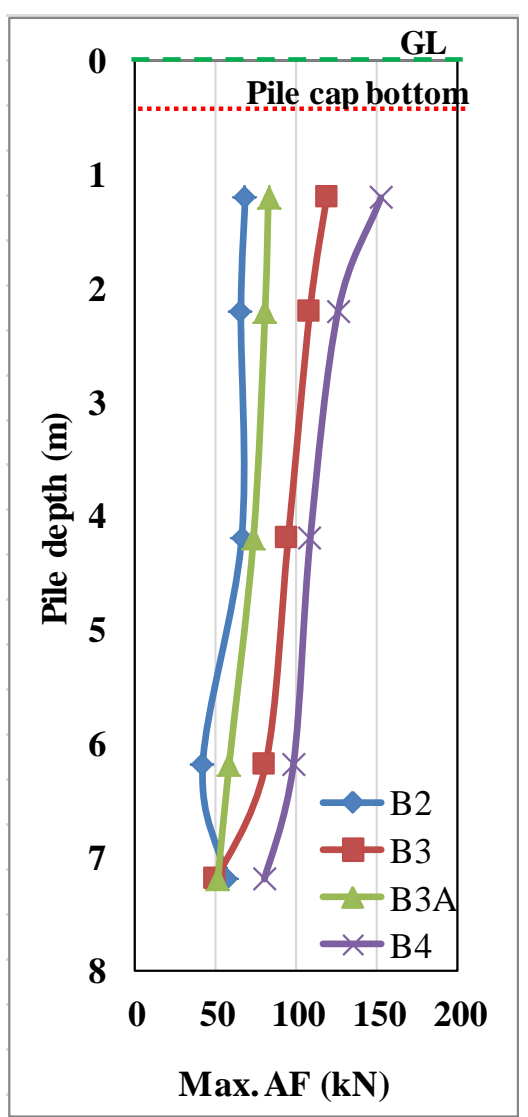

(a)

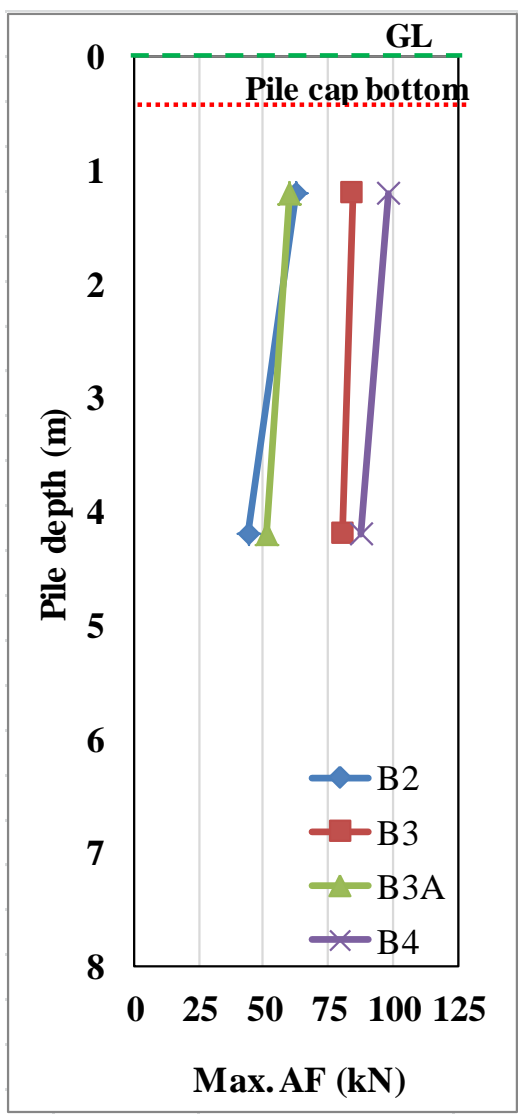

(b)

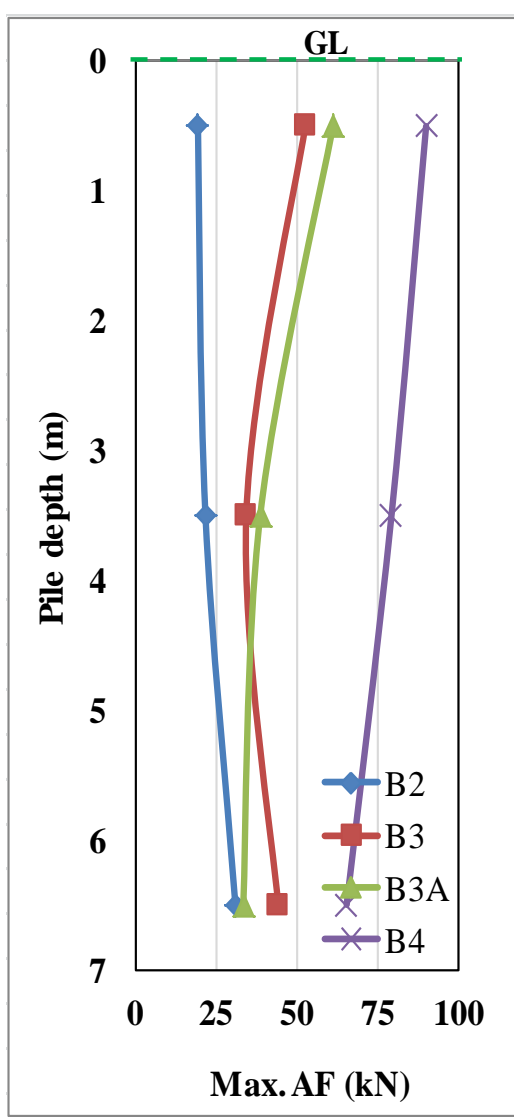

(c)

Fig. 10. The distribution of maximum AFs of (a) Pile A (b) Pile B (c) Pile C

As stated in section 2, nominally reinforced concrete piles were used in the field tests. For the nominally reinforced concrete pile, as recommended in BS 8004:1986 [26] and SS CP4:2003 [27], the allowable structural capacity of the pile can be calculated using Eq. (5). Thus, it gives the structural capacity of the designed pile $\left(Q_{s t}\right)$ is $2121 \mathrm{kN}$.

$$
\mathrm{Q}_{\mathrm{st}}=0.25 \mathrm{f}_{\mathrm{cu}} \mathrm{A}_{\mathrm{c}}
$$

where $A_{c}$ is the cross-sectional area of concrete and $f_{c u}$ is the compressive strength of the concrete and $0.25 f_{c u}$ is limited to $7.5 \mathrm{~N} / \mathrm{mm}^{2}$.

A pile subjected to a vertical compression load will be partially supported by the friction developed along the pile shaft, and partly by the resistance generated at the tip of the pile. Thus, the allowable geotechnical capacity of a pile is calculated as given in Eq. (6).

$$
\mathrm{Q}_{\mathrm{a}}=\frac{\mathrm{Q}_{\mathrm{s}}+\mathrm{Q}_{\mathrm{b}}}{\mathrm{F}_{\mathrm{s}}}
$$


where $Q_{s}$ is the ultimate shaft resistance, $Q_{b}$ is the ultimate base resistance, and $F_{s}$ is the geotechnical factor of safety, which in Singapore is commonly assumed to be between 2 and $2.5[27]$.

Ultimate shaft resistance, Qs, and ultimate base resistance, Qb, are calculated from Eqs. (7) and (8), respectively.

$$
\begin{aligned}
& \mathrm{Q}_{\mathrm{s}}=\sum_{\mathrm{i}=1}^{\mathrm{N}} \mathrm{f}_{\mathrm{si}} \mathrm{A}_{\mathrm{si}} \\
& \mathrm{Q}_{\mathrm{b}}=\mathrm{f}_{\mathrm{b}} \mathrm{A}_{\mathrm{p}}
\end{aligned}
$$

where $f_{s i}$ is the ultimate unit shaft resistance in layer $i, A_{s i}$ is the shaft area of pile in layer $i$, and $f_{b}$ is the ultimate unit base resistance, and $A_{p}$ is the pile base area.

The Singapore code for foundations, SS CP4:2003 [27] recommends the following Eqs. (9) and (10) to estimate the ultimate unit shaft resistance and ultimate unit base resistance of bored piles, respectively.

$$
\begin{aligned}
\mathrm{f}_{\mathrm{s}} & =\mathrm{k}_{\mathrm{s}} \mathrm{N}(\mathrm{kPa}) \\
\mathrm{f}_{\mathrm{b}} & =\mathrm{k}_{\mathrm{b}} 40 \mathrm{~N}(\mathrm{kPa})
\end{aligned}
$$

where $N$ is the SPT value of soil, $k_{s}$ is the skin friction coefficient, and $k_{b}$ is the base resistance coefficient. For residual soil of Bukit Timah granite, a value of $k_{s}$ between 1.5 and 2.5 is commonly adopted [27]. A value of $k_{b}$ depends on many factors and a value of $k_{b}$ between 1 and 3 is commonly adopted [27].

Boring log results from the soil investigation works were used to determine the geotechnical capacity of the pile and the values for the $k_{s}$ and $k_{b}$ were taken as 2.5 and 1, respectively. Thus, the ultimate shaft and base resistance were calculated as $807 \mathrm{kN}$ and $1131 \mathrm{kN}$, respectively, using Eqs. (7) to (10). By assuming the geotechnical factor of safety is 2, the geotechnical capacity of the pile was calculated as $969 \mathrm{kN}$, using Eq. (6). As calculated above, the structural and geotechnical capacities of the pile are $2121 \mathrm{kN}$ and $969 \mathrm{kN}$. Hence, the working load on the pile must be less than $969 \mathrm{kN}$. Based on the measured strains in strain gauges, the maximum axial force induced by blasting-induced ground vibration is about $152 \mathrm{kN}$. Since the maximum axial force on the pile is less than the axial load capacity of the pile, the pile is safe under the above blast tests. 
The ultimate moment capacity of the pile was determined by bending theory involving stressstrain relationships of concrete and steel. Fig. 11 shows the diagrams for ultimate moment capacity of the pile calculation. When determining the ultimate moment capacity of the pile following assumptions were made:

1) Plane cross-sections remain plane during bending.

2) The tensile strength of the concrete is equal to zero.

3) Perfect bond exists between steel and concrete.

4) Material safety factors were taken as $\gamma_{c}=1.5$ for concrete and $\gamma_{s}=1.15$ for steel.

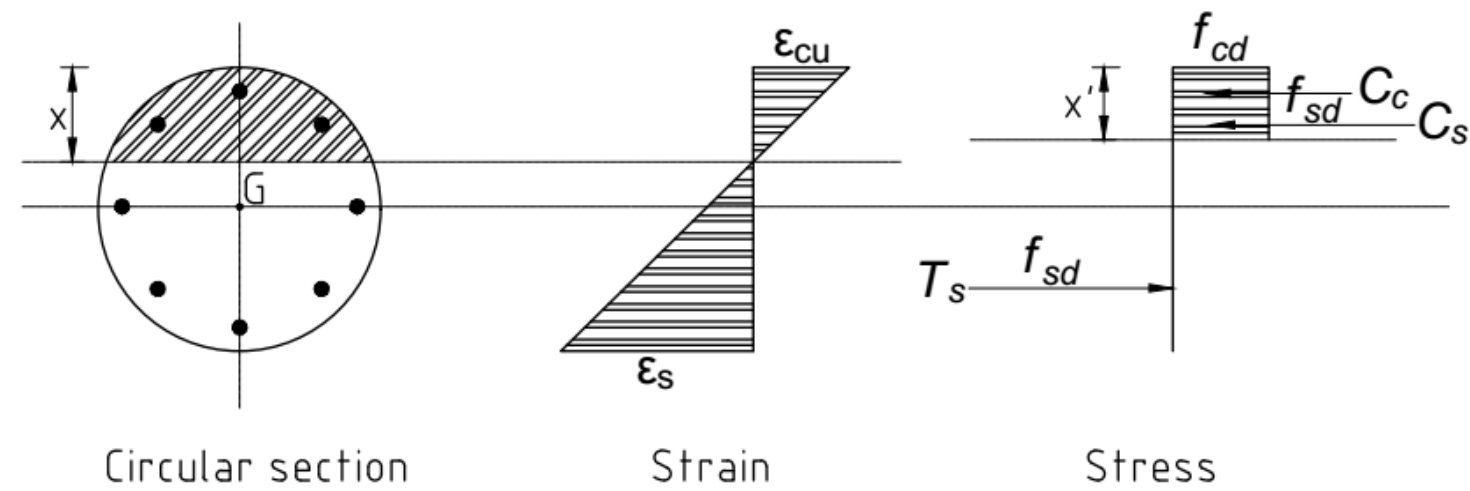

Fig. 11. Diagrams for the calculation of moment capacity of a circular RC section

The position of neutral axis, $x$, is calculated based on the force equilibrium as in Eqs. (11) to (14).

$$
\begin{aligned}
& \mathrm{N}=\mathrm{C}_{c}+C_{s}-T_{s} \\
& \mathrm{C}_{c}=\mathrm{f}_{c d} \mathrm{~A}_{c} \\
& \mathrm{C}_{s}=\mathrm{f}_{s d} \cdot \sum_{i=1}^{n} A_{s c i} \\
& \mathrm{~T}_{s}=\mathrm{f}_{s d} \cdot \sum_{i=1}^{n} A_{s t i}
\end{aligned}
$$

where $\mathrm{N}$ is the design compressive axial load, $C_{c}$ and $C_{s}$ are the compressive forces in concrete and steel reinforcement of the compression zone, respectively, and $T_{s}$ is the tensile force in the reinforcement of the tension zone. $A_{c}$ is the area of concrete of the compression zone and $A_{s c i}$ and $A_{s t i}$ represent the areas of the $i$-th reinforcement in the compression zone and the $i$-th reinforcement in the tension zone, respectively. $f_{c d}$ and $f_{s d}$ are the design values of concrete compressive strength and steel yield strength, respectively. 
The determination of location of the neutral axis was carried out by iteration method. Then, the design moment capacity of the pile, $M_{u l t}$, was calculated as in Eq. (15) and it was calculated as approximately $206 \mathrm{kNm}$. From the field test results, the calculated maximum bending moment on the pile is about $29 \mathrm{kNm}$. Since the maximum bending moment on the pile is less than the moment capacity of the pile, the pile is safe under the above blast tests. However, it should be noted that the pile ends moments are not measured in this test.

$$
\mathrm{M}_{u l t}=\mathrm{f}_{s d} \cdot \sum_{i=1}^{n} A_{s i} \cdot d_{s i}+\mathrm{f}_{c d} \mathrm{~A}_{\mathrm{c}} d
$$

where $A_{s i}$ is the area of the $i$-th reinforcement. $d_{s i}$ is the distance to centre of the $i$-th reinforcement from centroid of the section and $d$ is the distance to the resultant of the compression stress in concrete from the centroid of the section.

\section{Conclusions}

This paper summarised the field test results from a series of blasting tests conducted in Singapore at a site with residual soil overlying granitic rock. In the field tests, 3 piles of $600 \mathrm{~mm}$ in diameter were used and all the piles were instrumented with electrical resisting foil-type strain gauges. The strain gauges were attached on the piles to measure the bending moments and axial forces along the pile length. The moment distribution shapes differed in each test in accordance with the ground vibration intensity. The bending moment and axial force were maximum at the pile head in most of cases with fixed-head piles. However, the bending moment was maximum at close to the mid-height of the pile for the free-head pile.

The design axial load capacity and moment capacity of the pile were $969 \mathrm{kN}$ and $206 \mathrm{kNm}$, respectively. The maximum axial force and bending moment of the pile are about $152 \mathrm{kN}$ and $29 \mathrm{kNm}$, respectively. Since the maximum axial force and bending moment on the pile are less than the capacities of the pile, the pile is safe under the considered blast tests.

\section{Acknowledgment}

This material is based on research/work supported by the Land and Liveability National Innovation Challenge under L2 NIC Award No. L2NICCFP1-2013-1.

Any opinions, findings, and conclusions or recommendations expressed in this material are those of the author(s) and do not necessarily reflect the views of the L2 NIC. 
Assistance during the field tests given by the staff from JTC Corporation, Chye Joo Construction Pte Ltd, Asia Tunnelling and Construction Pte Ltd and Singapore Test Services are gratefully acknowledged.

\section{References}

[1] Jayasinghe L.B., Zhou H.Y., Goh A.T.C., Zhao Z.Y., and Gui Y.L., Pile response subjected to rock blasting induced ground vibration near soil-rock interface, Computers and Geotechnics, 82 (2017), pp. 1-15.

[2] Dusenberry D.O., Handbook for blast resistant design of buildings, 1st edition, John Wiley and Sons, 2010, pp. 512.

[3] Liao S., Li W., Fan Y., Sun X., and Shi Z., Model test on lateral loading performance of secant pile walls, Journal of Performance Constructed Facilities, 28(2) (2014), pp. 391-401.

[4] Abdoun T., Dobry R., and O'Rourke T.D., Centrifuge and numerical modeling of soil-pile interaction during earthquake induced soil liquefaction and lateral spreading, Observation and modeling in numerical analysis and model tests in dynamic soil-structure interaction problems, GSP Geotechnical Special Publication No. 64, ASCE, 1997, pp. 76-90.

[5] Wilson D.W., Boulanger R.W., and Kutter B.L., Observed seismic lateral resistance of liquefying sand, Journal of Geotechnical and Geoenvironment Engineering, 126(10) (2000), pp. 898-906.

[6] Shim H-S., Response of piles in saturated soil under blast loading, Doctoral thesis, University of Colorado, Boulder, US, 1996.

[7] Kamijo N., Saito H., Kusama K., Kontani O., and Nigbor R., Seismic tests of a pilesupported structure in liquefiable sand using large-scale blast excitation, Nuclear Engineering and Design, 228 (2004), pp 367-376.

[8] Ashford S.A., Juirnarongrit T., Sugano T., and Hamada M., Soil-pile response to blastinduced lateral spreading. I: Field test, Journal of Geotechnical and Geoenvironmental Engineering, ASCE, 132(2) (2006), pp 152-162.

[9] Durante M.G., Di Sarno L., Mylonakis G., Taylor C.A., and Simonelli A.L., Soil-pilestructure interaction: experimental outcomes fromshaking table tests, Earthquake Engineering and Structural Dynamics, 45(7) (2016), pp. 1041-1061. 
[10] Nikolaou S., Mylonakis G., Gazetas G., and Tazoh T., Kinematic pile bending during earthquakes: analysis and field measurements, Geotechnique, 51(5) (2001), pp. 425-440.

[11] Padron L.A., Aznarez J.J., and Maero O., Dynamic analysis of piled foundations in stratified soils by a BEM-FEM model, Soil Dynamics and Earth quake Engineering, 5 (2008), pp. 333-346.

[12] Dezi F., Carbonari S., and Leoni G., A model for the 3D kinematic interaction analysis of pile groups in layered soils, Earthquake Engineering and Structural Dynamics, 38 (2009), pp. 1281-1305.

[13] Trochanis A, Bielak J, and Christiano P., Three dimensional nonlinear study of piles. Journal of Geotechnical Engineering (ASCE), 117(3) (1991), pp. 429-447.

[14] Wu G., and Finn W., Dynamic elastic analysis of pile foundations using finite element method in the time domain, Canadian Geotechnical Journal, 34(1) (1997), pp. 44-52.

[15] Maheshwai B.K., Truman K.Z., EI Naggar M.H., and Gould P.L., Three Dimensional Finite Element Nonlinear Dynamic Analysis of Pile Groups for Lateral Transient and Seismic Excitations, Canadian Geotechnical Journal, 41 (2004), pp. 118-133.

[16] Liyanapathirana D.S., and Poulos, H.G., Seismic Lateral Response of Piles in Liquefying Soil, Journal of Geotechnical and Geo-environmental Engineering, 131(2) (2005), pp. 1466-1479.

[17] Martinelli M., Burghignoli A., and Callisto L., Dynamic response of a pile embedded into a layered soil, Soil Dynamics and Earthquake Engineering, 87 (2016), pp. 16-28.

[18] Hao H., Pan T.C., and Zhao Z., Inelastic responses of pile-soil system to blast loads, WIT Transactions on the Built Environment, 8 (1994).

[19] Huang B., Gao Q., Wang J., Jiang X., Wang X., Jiang B., and Wu W., Dynamic analysis of pile-soil-structure interaction system under blasting load, Applied Mechanics and Materials, 638-640 (2014), pp 433-436.

[20] Jayasinghe, L.B., Thambiratnam, D.P., Perera, N., and Jayasooriya, J.H.A.R., Blast response of reinforced concrete pile using fully coupled computer simulation techniques, Computers and Structures, 135 (2014), pp. 40-49. 
[21] Jayasinghe L.B., Thambiratnam D.P., Perera N., and Jayasooriya J.H.A.R., Blast response and failure analysis of pile foundations subjected to surface explosions, Engineering Failure Analysis, 39 (2014), pp 41-54.

[22] Chang M.F., and Broms B.B., Design of bored piles in residual soils based on field performance data, Canadian Geotechnical Journal, 28(2) (1991), pp. 200-209.

[23] Zhao J., Broms B.B., Zhou Y., and Choa V. (1994), A study of the weathering of the Bukit Timah granite, parts A and B. Bulletin of the International Association of Engineering Geology 49, pp. 97-105; 50, pp. 105-111.

[24] Sharma J.S., Chu J., and Zhao J. (1999), Geological and Geotechnical Features of Singapore: an Overview, Tunnelling and Underground Space Technology, 14(4), pp. 419431.

[25] Hijikata K., Ishida T., Tanaka H., Koyamada K., Miyamota Y., Kontani O., and Nigbor R., Experimental study on soil-pile-structure interaction in liquefiable sand subjected to blastinduced ground motion, $13^{\text {th }}$ World Conference on Earthquake Engineering, Canada, August 2004.

[26] BS 8004, British standard: Code of practice for foundations, 1986.

[27] SS CP4, Singapore standard: Code of practice for foundations, 2003. 